\title{
Design of Heat Exchangers and Converting into Thermodynamics to Produce Electricity
}

\author{
V. Savitri ${ }^{1}$, M. Ganesh Kumar ${ }^{2}$ \\ ${ }^{1}$ M.Tech Thermal Engineering, Sanketika Institute of Technology and Management, Visakhapatnam \\ ${ }^{2}$ Assistant Professor, Sanketika Institute of Technology and Management, Visakhapatnam
}

\begin{abstract}
Heat Exchangers plays a vital role in Industries. Using Heat Exchangers in this Project with Two Hot Junctions producing Electricity using Thermodynamic module called See back Effect, where it is a phenomenon in which a temperature difference between two dissimilar electrical conductors or semiconductors produces a voltage difference between the two substances. The main purpose of this project is, In Industries heat will be more when compared to environment temperature. Using waste heat we are producing Electricity to utilize for Electronic Peripherals.
\end{abstract}

Keywords: Heat Exchangers, Thermal Energy, Thermodynamics.

\section{Introduction}

A heat exchanger is a device that is used to transfer thermal energy (enthalpy) between two or more junctions, between solid surfaces called plastrons or between solid particulates and a fluid, at different temperatures and in thermal contact. In heat exchangers, there are usually no external heat and work interactions. We give electricity to produce heat because no external temperature will be used. In Typical applications involve heating or cooling of a fluid stream of concern and evaporation or condensation of single- or multicomponent. In other applications, the objective may be to recover or reject heat, or sterilize, pasteurize, fractionate, distill, concentrate, crystallize, or control a process. In a few heat exchangers, the exchanging heat is in direct contact. In most heat exchangers, heat transfer between takes place through a separating metal in a transient manner via thermal energy storage and release through the exchanger surface or matrix are referred to as indirect transfer type, or simply regenerators it is also known as TEG (thermo electric Generators)

\section{Block Diagram}

The Block Diagram Explains clear picture of connection in [1].Structural diagram explain in graphical module the junction and propeller connection at[2].Placing of See back or peltier module is placed on energy conversions [3]. The voltage measuring and regenerator of battery and signal graphs is measured in Lab view with temperature sensor.

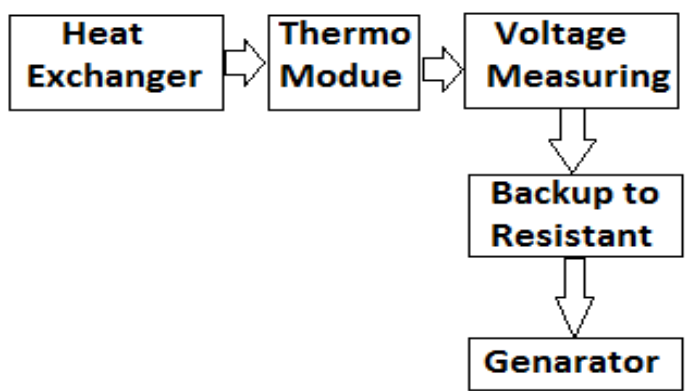

Figure 1: Block Diagram

\subsection{Measurements of Heat Exchangers}

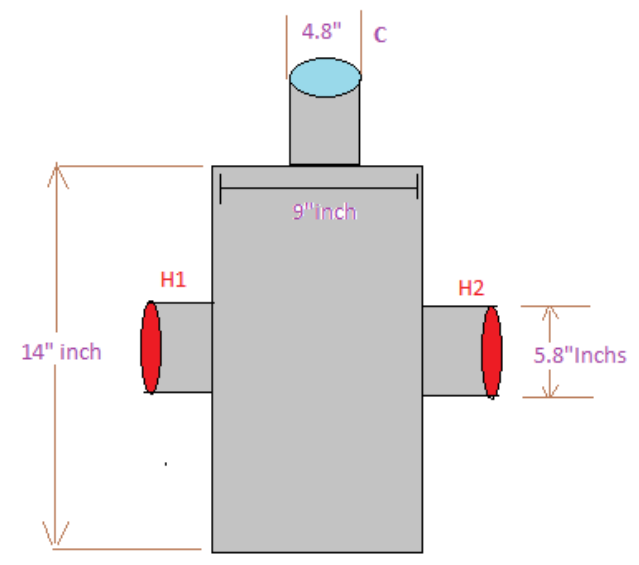

\subsection{Thermo Electric Generators}

TEC1-12706 Heat sink Thermoelectric Cooler Cooling Peltier Plate Module 12V 60W Features: - Get ice cold in minutes or heat to boiling by simply reversing the polarity, Used for numerous applications from CPU coolers to alternate power sources, or even for your own custom car drink warmer/cooler. - Since they consist primarily of semiconductor material sandwiched between ceramic plates and have no moving parts -These devices must be used in conjunction with a heat sink to avoid burned - Each device is full inspected and tested - Fitted with 6-inch insulated leads Technical Specifications: -Model: TEC1-12706 -Size: 40mm x 40mm x 4mm -Operates from 0 15.2V DC and 0 6A Operates Temperature: -30 to 70 -Max power consumption: 60 Watts -Original box: NO -Net weight: 22g -Package weight: $31 \mathrm{~g}$ 


\section{International Journal of Science and Research (IJSR) \\ ISSN (Online): 2319-7064}

Index Copernicus Value (2013): 6.14 | Impact Factor (2013): 4.438

\section{Specifications}

\begin{tabular}{||l|c|c||}
\hline Hot Side Temperature $\left({ }^{\circ} \mathrm{C}\right)$ & $25^{\circ} \mathrm{C}$ & $50^{\circ} \mathrm{C}$ \\
\hline Qmax (Watts) & 50 & 57 \\
\hline Delta Tmax ( $\left.{ }^{\circ} \mathrm{C}\right)$ & 66 & 75 \\
\hline Imax (Amps) & 6.4 & 6.4 \\
\hline Vmax (Volts) & 14.4 & 16.4 \\
\hline Module Resistance (Ohms) & 1.98 & 2.30 \\
\hline
\end{tabular}

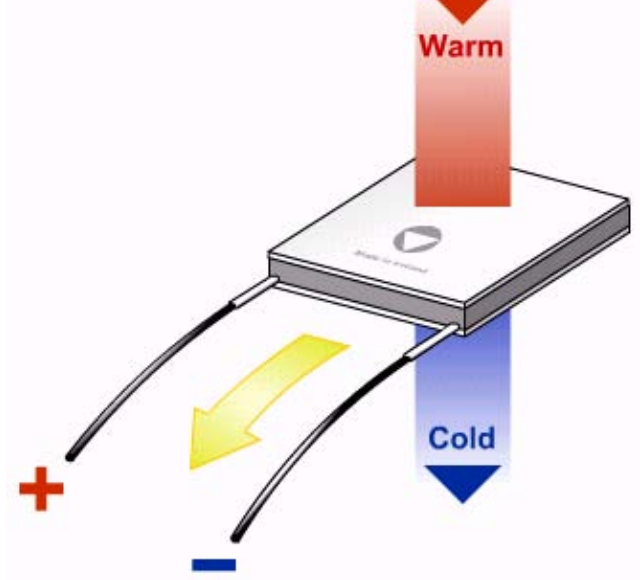

Figure 3: Thermo Electric Modules (TEG)

\section{Internal Process for Peltier}

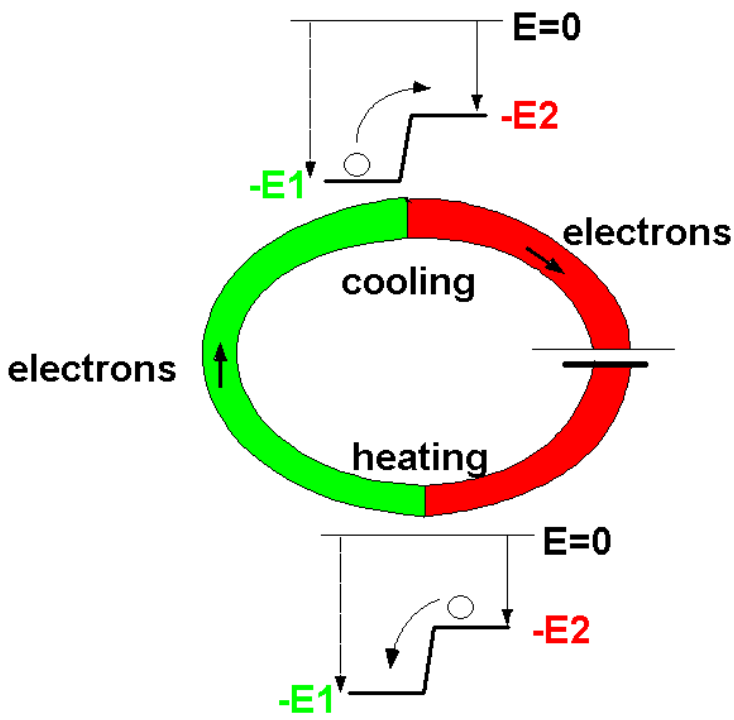

\subsection{Fabrication of the Project}

\section{Foldable Metal Sheet}

Sheet metal is metal formed by an industrial process into thin, flat pieces. It is one of the fundamental forms used in metalworking and it can be cut and bent into a variety of shapes. Countless everyday objects are constructed with sheet metal. Thicknesses can vary significantly; extremely thin thicknesses are considered foil or leaf, and pieces thicker than $6 \mathrm{~mm}(0.25 \mathrm{in})$ are considered plate. Sheet metal is available in flat pieces or coiled strips. The coils are formed by running a continuous sheet of metal through a roll

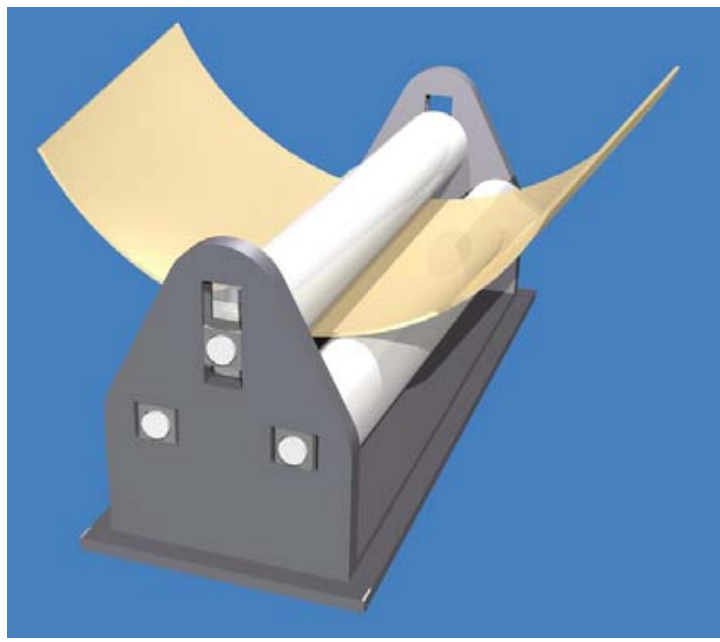

Figure 4: Fabrications

Slitter. The thickness of sheet metal is commonly specified by a traditional, non-linear measure known as its gauge. The larger the gauge number, the thinner the metal. Commonly used steel sheet metal ranges from 30 gauges to about 7 gauges. Gauge differs between ferrous (iron based) metals and nonferrous metals such as aluminum or copper; copper thickness, for example are measured in ounces (and represent the thickness of 1 ounce of copper rolled out to an area of 1 square foot).

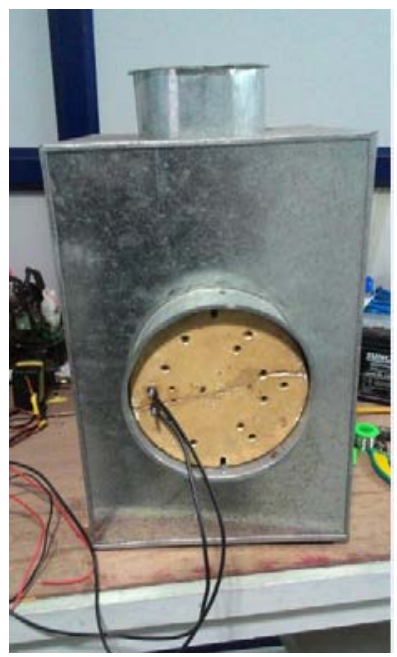

Figure 5: GA Metallic Sheet with heat Exchanger

\subsection{Heat Induction Exchangers}

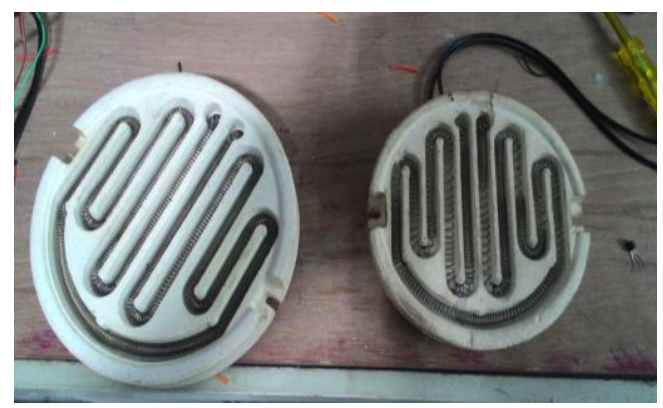




\section{International Journal of Science and Research (IJSR) \\ ISSN (Online): 2319-7064 \\ Index Copernicus Value (2013): 6.14 | Impact Factor (2013): 4.438}

The induction exchanger is used for adjustable heating facilities. Different heat can be adjusted for boiling, stewing. It also takes minimal time to cool. Electrostatic induction is a redistribution of electrical charge in an object, caused by the influence of nearby charges. In the presence of a charged body, an insulated conductor develops a positive charge on one end and a negative charge on the other end. Induction was discovered by British scientist John Canton in 1753 and Swedish professor Johan Carl Wilcke in 1762.Electrostatic generators, such as the Wimshurst machine, the Van de Graff generator and the electrophorus, use this principle. Due to induction, the electrostatic potential (voltage) is constant at any point throughout a conductor. Induction is also responsible for the attraction of light nonconductive objects, such as balloons, paper or Styrofoam scraps, to static electric charges. Electrostatic induction should not be confused with electromagnetic induction.

\subsection{ATmega Microcontroller}

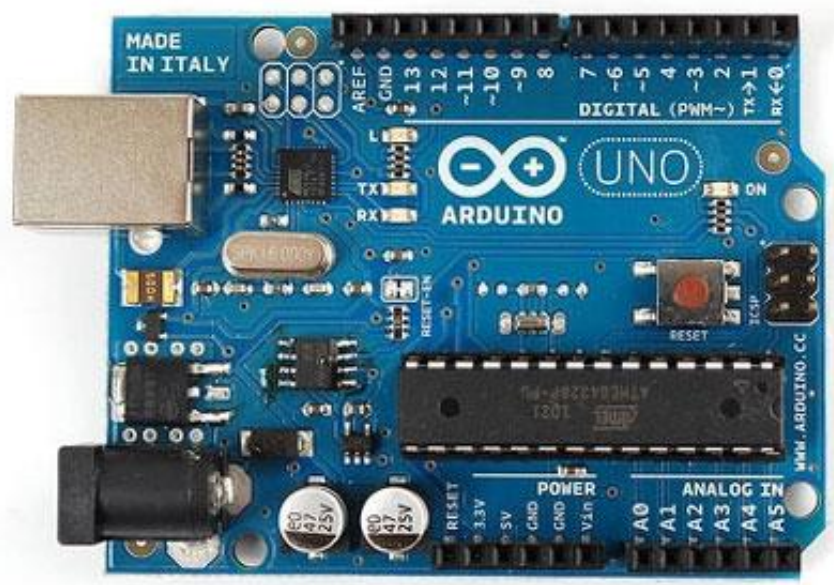

Arduino is an open-source computer hardware and software company, project and user community that designs and manufactures microcontroller-based kits for building digital devices and interactive objects that can sense and control the physical world. This microcontroller is utilized to measure the temperature sensor to control various applications and Graphs monitored in Xls and Lab view for user friendly where it can identify the graphical representation. Which is shown below?

\subsection{Tables}

Table 1: Time Vs Temperature

\begin{tabular}{|l|c|c|}
\hline S. No & Time & Temperature \\
\hline 1 & 0 & 32 \\
\hline 2 & 1 & 33 \\
\hline 3 & 2 & 34 \\
\hline 4 & 3 & 36 \\
\hline 5 & 4 & 38 \\
\hline 6 & 5 & 40 \\
\hline 7 & 6 & 42 \\
\hline
\end{tabular}

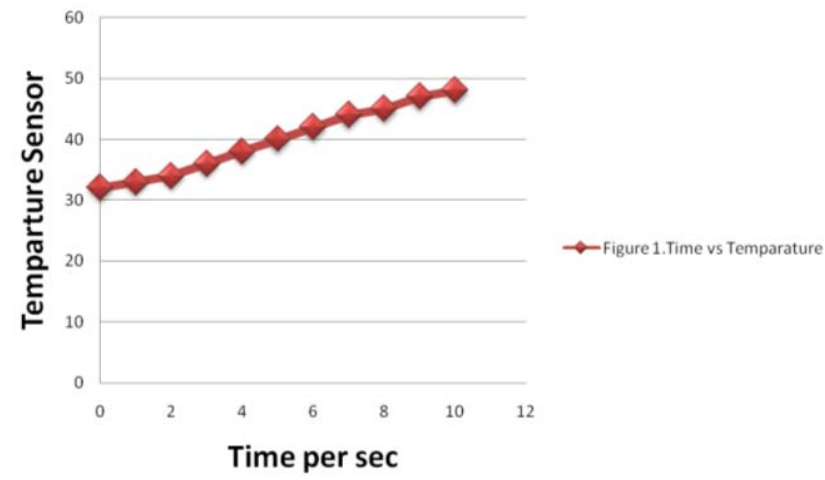

Figure 1: Testing Recorded in Xls with Temp sensor

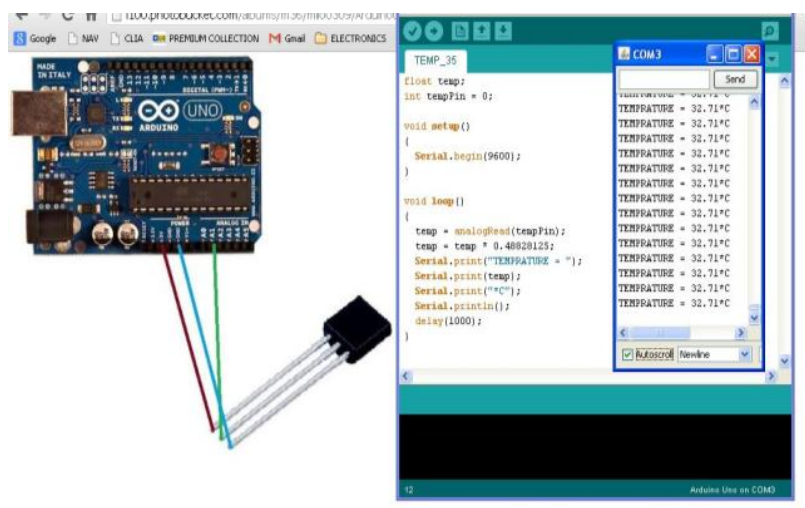

Figure: Temperature sensor Reading from Induction

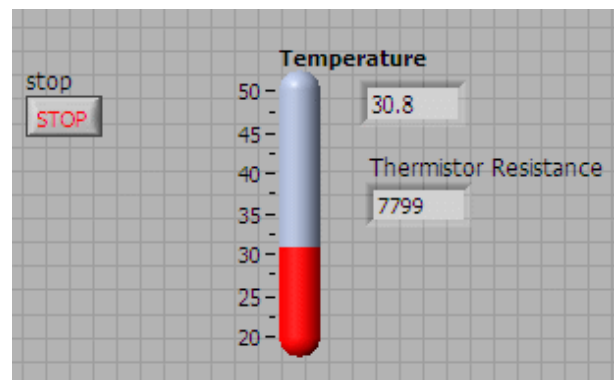

Figure: Lab view Temperature Monitoring

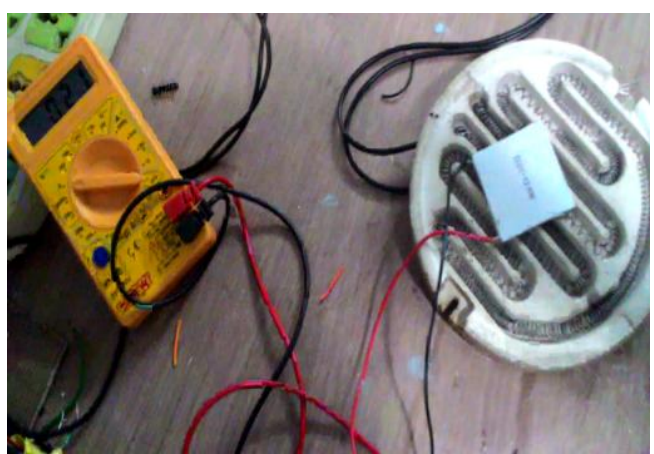

Figure: Voltage Measuring with TEG 


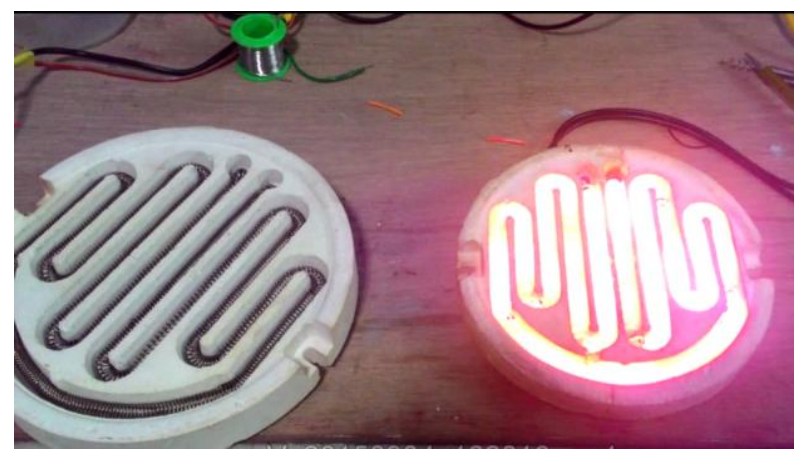

Figure: Induction for Waste Heat 230vAC

\subsection{Sections headings}

Section headings come in several varieties:

1) first level headings: 1. Introduction

2) second level: 2. Block Diagram

3) second level: 2.1 Thermo Electric generator

4) third level: 3.1Fabrication of the Project

5) third level: 3.2 Heat Induction Exchangers

6) third level: 3.3 At mega Microcontrollers

7) third level: 3.4 Tables Headings

8) third level: 3.4 Section forth level: (a) Heading 4

9) fifth level: (1) Heading 5

\section{Equations}

The model presented here has served well in a variety of designs. It requires, as input, only numbers that are routinely provided in TEC datasheets. Though it's a simplification of the gory details of TEC physics, the model is realistic enough to be used in most TEC design applications.

The model predicts TEC thermal load temperature (T1) as a function of load heat production, TEC data-sheet numbers, heat sink parameters, TEC drive current, and ambient temperature (T3). It looks like this:

$$
\begin{gathered}
\mathrm{T} 1=(-\mathrm{P} * \text { Itec }+ \text { Itec2 } * \mathrm{Rp} / 2+\mathrm{Q} 1) /(\mathrm{C} 1+\mathrm{Cp})+(\mathrm{Q} 1+\mathrm{Itec} 2 \\
* \mathrm{Rp}) /(\mathrm{Ch}+\mathrm{T} 3)
\end{gathered}
$$

Where

$\mathrm{P}=$ Peltier cons $=(\mathrm{Qmax}+\operatorname{Imax} 2 * \mathrm{Rp} / 2) / \mathrm{Imax}$

Qmax $=$ max heat transfer from TEC data sheet (watts)

$\mathrm{Rp}=\mathrm{TEC}$ resis $=\mathrm{Vmax} / \mathrm{Imax}$

$=$ TEC data sheet drive ratings

Itec $=$ TEC drive current (amperes)

$\mathrm{Q} 1=$ heat produced by thermal load watts)

$\mathrm{C} 1=$ conduvity $\left(\right.$ watts $/{ }^{\circ} \mathrm{C}$ ) of thermal load to ambient

$\mathrm{Cp}=\mathrm{TEC}$ thermal conductivity

$=\mathrm{Qmax} / \Delta \mathrm{Tmax}$ from TEC data sheet

$\mathrm{Ch}=$ heatsink thermal conductivity to ambient

T3 = ambient temperature

\section{References}

[1] "Seeback Effect"

http://searchnetworking.techtarget.com/definition/Seebe ck-effect

[2] "Thermodynamics Module" http://www.livescience.com/50776-thermodynamics.html

[3] "Heat Exchanger and its Ratios" https://en.wikipedia.org/wiki/Heat_exchanger

[4] "Interfacing Entire projects with Labview" http://www.instructables.com/id/Arduino-andLabVIEW/ 